\title{
METODE DRIVE TEST SEBAGAI MONITORING UNJUK KERJA JARINGAN NIRKABEL PADA GEDUNG - GEDUNG DI LINGKUNGAN UNIVERSITAS PAPUA
}

\author{
Rantika Tri Septyani Simanjuntak ${ }^{1}$, Parma Hadi Rantelinggi*2, Kristia Yuliawan ${ }^{3}$ \\ 1,2,3 Program Studi Teknik Informatika, Universitas Papua, Manokwari \\ Email: ${ }^{1}$ rantikasimanjuntak139@gmail.com, ${ }^{2}$ p.rantelinggi@unipa.ac.id, ${ }^{3}$ k.yuliawan@unipa.ac.id \\ *Penulis Korespondensi
}

(Naskah masuk: 18 Desember 2019, diterima untuk diterbitkan: 26 November 2020)

\begin{abstract}
Abstrak
Universitas Papua telah memberikan layanan internet yang di bagikan pada setiap gedung fakultas dengan Wi-Fi sebagai media berbagi, dalam penelitian ini kegiatan yang dilakukan yaitu mengamati dan menganalisis kualitas jaringan Wi-Fi yang telah tersedia. Dalam penelitian ini cara melakukan pengukuran kualitas jaringan nirkabel ini menggunakan metode Drive Test, dimana metode ini mengukur secara manual dan menghimpun data secara waktu nyata menggunakan beberapa parameter antara lain Bandwidth, Delay dan Packet Loss. Dalam penelitian ini pengumpulan data dengan menggunakan dua aplikasi jaringan yaitu Nagios XI dan Wireshark. Untuk melihat kualitas jaringan dari hasil percobaan yang dilakukan maka digunakan standar TIPHON. Hasil perolehan pengukuran yang di dapat adalah kualitas pemakaian Bandwidth sudah baik, karena tidak melebihi kapasitas yang telah di alokasikan pada setiap gedung di Universitas Papua dan dapat dilihat dari nilai rata-rata Delay dan Packet Loss pada setiap gedung. Hasil pengujian kualitas layanan jaringan Wi-Fi menunjukkan indeks nilai pada standar TIPHON adalah 4, yang artinya sangat bagus. Karena pengujian Delay nilai tertinggi yang di peroleh bila di ukur dengan Nagios XI adalah $76 \mathrm{~ms}$ dan terendah adalah $21,8 \mathrm{~ms}$, untuk pengukuran menggunakan Wireshark nilai tertinggi adalah $72,4 \mathrm{~ms}$ dan terendah adalah $10 \mathrm{~ms}$. Untuk Packet Loss hasil yang diperoleh yaitu $0 \%$ bila di ukur dengan Nagios XI dan Wireshark.
\end{abstract}

Kata kunci: drive test, jaringan nirkabel, kualitas pelayanan jaringan, monitoring

\section{DRIVE TEST METHOD AS A MONITORING PERFORMANCE OF WIRELESS NETWORK IN BUILDINGS AT UNIVERSITAS PAPUA}

\begin{abstract}
Universitas Papua has provided internet services that are shared in every faculty building with Wi-Fi as a sharing medium, in this research the activities carried out were observing and analyzing the quality of available Wi-Fi networks. In this research, how to measure the quality of this wireless network using the Drive Test method, where this method measures manually and collects data in real-time using several parameters including Bandwidth, Delay and Packet Loss. In this research, data collection using two network applications, namely Nagios XI and Wireshark. To looks at the quality of the network from the results of experiments conducted, the TIPHON standard is used. The results obtained are that the quality of using Bandwidth is good because it does not exceed the capacity that has been allocated for each building at Universitas Papua and can be seen from the average value of Delay and Packet Loss in each construction. The results of testing the quality of Wi-Fi network services indicate that the index value on the TIPHON standard is 4, which means it is excellent. Because of the Delay test, the highest value obtained when measured by Nagios XI is $76 \mathrm{~ms}$, and the lowest is $21.8 \mathrm{~ms}$, for measurements using Wireshark, the highest value is $72.4 \mathrm{~ms}$, and the lowest is $10 \mathrm{~ms}$. For Packet Loss, the results obtained are 0\% when measured by Nagios XI and Wireshark.
\end{abstract}

Keywords: drive test, wireless network, quality of network services, monitoring

\section{PENDAHULUAN}

Perkembangan Teknologi Informasi (TI) saat ini berperan di Lembaga Pemerintahan maupun Non Pemerintah, TI menjadi tulang punggung kebutuhan bahkan lembaga pendidikan dalam mencapai tujuan masing-masing. Universitas Papua (UNIPA) merupakan salah satu lembaga pendidikan Perguruan Tinggi Negeri yang berada di Provinsi Papua Barat, 
telah berkembang pesat membawa penduduk Papua Barat menuju masyarakat yang paham perkembangan TI.

Dalam mencapai tujuannya, UNIPA juga memanfaatkan TI dengan menyediakan layanan jaringan $\mathrm{Wi}-\mathrm{Fi}$ yang merupakan salah satu kemajuan dalam memanfaatkan teknologi informasi pada setiap gedung, seperti gedung Fakultas Teknik, gedung Fakultas Kehutanan, gedung Fakultas Pertanian, gedung Jurusan Teknik Informatika dan gedung Unit Pelayanan Teknis Teknologi Informasi dan Komunikasi (UPT.TIK UNIPA). Pada setiap gedung tersebut dipasang lebih dari satu perangkat access point yang merupakan perangkat radio lokal dalam gedung yang merupakan jembatan komunikasi dengan Wi-Fi (Gunantara, dkk., 2018; Banani, Eckford \& Adve, 2015; Xie, dkk., 2016), tujuannya untuk memudahkan setiap pegawai, dosen dan mahasiswa dalam mengakses jaringan internet kapan pun di area kampus.

Namun dalam mengakses jaringan di dalam ruangan tersebut rentan perubahan dan pelemahan sinyal (Yu, dkk., 2014), muncul pula beberapa permasalahan yang ada, salah satunya kecepatan bandwidth pada setiap gedung berbeda-beda sehingga menyebabkan delay dalam proses transfer data (Wulandari, Perdana \& Negara, 2017; TorresSospedra, dkk., 2015). Sehingga manajemen jaringan di butuhkan untuk mengatur infrastruktur jaringan dan hak akses dalam jaringan. Hierarchical Token Bucket sebagai metode sistem manajemen bandwidth yang dapat menerapkan QoS untuk menejemen bandwidth dalam jaringan (Antodi, Prasetijo dan Widianto, 2017). Manajemen cerdas pada jaringan heterogen dalam mengatasi beban jaringan, koeksistensi dan manajemen jaringan secara global merupakan model peletakan dasar koneksi untuk komunikasi antar pengguna (Bosch, $\mathrm{dkk}, 2020)$. Kemudian manajemen jaringan seperti teknologi Software Defined Networking (SDN) adalah teknologi yang memingkatkan jaringan komputasi yang berfokus kepada fungsi jaringan serta strategi perangkat lunak jaringan sensor nirkabel sebagai upaya dalam meningkatkan fungsi aplikasi dalam infrastruktur yang di pantau (Modieginyane, dkk, 2018). Model manajemen jaringan Software Define Wireless Sensor Network (SDWSN) yang di kombinasi dengan Discrete Event Simulation (DES) dan SDN kemudian di implementasikan dengan pendekantan model Driven Service Abstraction Layer (MD - SAL) menunjukkna hasil arus lalu lintas jaringan meningkat dan delay transmisi berkurang sertas konsumsi energi yang rendah (Modieginyane, Malekian dan Letswamotse, 2019).

Oleh karena itu dirasa perlu dilakukannya analisis dan monitoring jaringan Wi-Fi yang merupakan bagian yang tidak terpisahkan dari manajemen jaringan, untuk mengetahui kualitas jaringan pada masing-masing gedung yang ada (İlçi,
Gülal \& Alkan, 2018), hal ini merupakan tantangan penelitian dalam menyediakan layanan jaringan nirkabel. Kontribusi dari penelitian ini membahas mengenai analisa kualitas jaringan Wi-Fi yang diamati secara waktu nyata dengan metode Drive Test.

Ada berbagai macam aplikasi yang bisa dimanfaatkan dalam pengukuran kualitas jaringan (Linawati, Gunantara \& Gunawan, 2015), tetapi dalam penelitian ini ada dua aplikasi yang digunakan untuk monitoring jaringan Wi-Fi, yaitu aplikasi Wireshark dan Nagios XI, dengan skenario uji coba di simulasikan dengan menggunakan ping, kemudian data hasil monitoring dari penelitian ini di analisa menggunakan parameter Quality of Service (QoS) seperti Bandwidth, Packet Loss dan Delay untuk mengetahui kualitas jaringan dalam setiap gedung di UNIPA.

Struktur dalam penulisan penelitian ini terbagi atas beberapa tahapan sebagai berikut Bagian II menjelaskan metode yang digunakan, hasil dan diskusi dijelaskan pada Bagian III, penelitian ini disimpulkan pada Bagian IV.

\section{METODE PENELITIAN}

Dalam bagian ini dijelaskan secara ringkas tentang Monitoring Jaringan, QoS dan metode Drive test.

\subsection{Monitor Jaringan}

Sistem monitor jaringan merupakan serangkaian aktifitas dalam mengumpulkan dan melakukan analisis data propagasi sinyal dan lalu lintas jaringan yang bertujuan untuk memanfaatkan semua sumber daya yang tersedia (Bobescu \& Alexandru, 2015), dalam komunikasi antara parangkat dalam satu infratruktur (Setiyono, Pramukantoro \& Amron, 2017). Sistem monitoring ini merupakan bagian dari manajemen jaringan. Sistem monitor jaringan terbagi dua macam, yang pertama connection monitoring yang merupakan cara monitor jaringan dengan melakukan tes ping antara stasiun monitor dengan perangkat yang menjadi objek tujuan, sehingga dapat diketahui apabila tidak terjadi koneksi. Sistem monitoring yang kedua disebut Traffic Monitoring merupakan cara melihat paket secara langsung dari lalu lintas jaringan, sehingga menghasilkan laporan berdasar pada pemantauan lalu lintas jaringan.

\subsection{QoS}

Quality of Service (QoS) adalah kemampuan dari sebuah layanan untuk menjamin performansi dan merupakan parameter untuk mengukur kualitas dari sebuah layanan. Tujuan desain QoS untuk menolong pengguna akhir agar lebih produktif dengan memastikan pengguna memperoleh performansi yang andal dari berbagai aplikasi berbasis jaringan. 
QoS berdasar pada kemampuan jaringan menyediakan layanan yang lebih baik pada lalu lintas jaringan melalui teknologi yang berbeda-beda (Simanjuntak, Nurhayati \& Widianto, 2016). QoS memiliki tantangan sendiri dalam penelitian jaringan yang berbasis pada IP dan internet secara keseluruhan (Saputra \& Sulistyo, 2017).

Untuk memenuhi kebutuhan layanan yang berbeda dengan memanfaatkan infrastruktur yang sama, QoS mampu untuk menjelaskan berbagai atribut layanan yang tersedia, baik secara kualitatif maupun kuantitatif (Amron, Pramukantoro \& Data, 2016). Tiga ukuran yang dipakai dalam mengamati QoS di penelitan ini antara lain bandwidth, delay dan packet loss yang dibahas satu per satu dalam artikel ini.

Delay dan Packet loss pada suatu jaringan diuji dengan menggunakan penerapan jaringan versi Telecommunication and Internet Protocol Harmonization Over Network (TIPHON) (Wulandari, 2016), dapat dilihat pada Tabel 1 untuk Packet Loss.

Tabel 1. Packet Loss Versi TIPHON (Wulandari, 2016)

\begin{tabular}{lcc}
\hline $\begin{array}{c}\text { Kategori } \\
\text { Degredasi }\end{array}$ & Packet Loss & Indeks \\
\hline Sangat Bagus & 0 & 4 \\
Bagus & 3 & 3 \\
Sedang & 15 & 2 \\
Jelek & 25 & 1 \\
\hline
\end{tabular}

Tabel 2 berguna untuk mengukur standar Delay versi TIPHON.

\begin{tabular}{llc}
\multicolumn{2}{c}{ Tabel 2. Delay Versi TIPHON (Wulandari, 2016) } \\
\hline \begin{tabular}{c} 
Kategori \\
\multicolumn{1}{c}{ Latensi }
\end{tabular} & Besar Delay (ms) & Indeks \\
\hline Sangat Bagus & $<150 \mathrm{~ms}$ & \\
Bagus & $150 \mathrm{~ms} \mathrm{~s} / \mathrm{d} 300 \mathrm{~ms}$ & 3 \\
Sedang & $300 \mathrm{~ms} \mathrm{~s} / \mathrm{d} 450 \mathrm{~ms}$ & 2 \\
Jelek & $>450 \mathrm{~ms}$ & 1 \\
\hline
\end{tabular}

Selanjutnya adalah gambaran singkat mengenai Bandwidth, Delay dan Packet Loss.

\section{a. Bandwidth}

Jangkauan frekuensi berdasarkan luas dan besarnya yang dimanfaatkan dalam media transmisi disebut dengan Bandwidth. Dalam cakupannya, yang dapat membedakan komponen pada sinyal frekuensi rendah dan frekuensi tinggi. Hertz merupakan satuan jumlah gelombang yang di pakai sebagai ukuran frekuensi sinyal. Bandwidth dimanfaatkan untuk persamaan kecepatan transfer data yang sering digunakan berdasarkan jumlah Bandwidth dalam satuan bps (bit per second), kadang ditampilkan dalam Bps (Bytes per second).

\section{b. Packet Loss}

Ukuran yang menerjemahkan pola pada kondisi di mana menghitung banyaknya paket yang hilang di sebut dengan Packet Loss (Rantelinggi \& Djanali, 2015), penyebabnya karena proses tabrakan dan kemacetan lalu lintas data dalam suatu jaringan dan ini mempunyai pengaruh pada aplikasi, karena retransmisi akan mengurangi kemampunan jaringan secara umum, walaupun bandwidth tersedia untuk perangkat aplikasi tersebut. Untuk mencari Packet Loss maka digunakan Persamaan (1).

packet loss $=\frac{y}{A} \times 100$

Keterangan :

$\mathrm{y}=$ Paket data dikirim - Paket data diterima

$A=$ Paket data dikirim

c. Delay

Waktu tempuh yang diperlukan oleh data agar mencapai jarak asal ke tujuan disebut dengan Delay. Selain jarak, media fisik dan waktu proses yang lama juga meruapakan faktor penyebab Delay (Rantelinggi, Paiki \& Rantelobo, 2017). Persamaan (2) adalah persamaan besarnya delay yang dapat diklasifikasikan sebagai berikut:

Delay $=\frac{\text { packet lenght }}{\text { link bandwith }}$

\subsection{Drive Test}

Drive test merupakan model yang dialamatkan untuk menghimpun data dari hasil pengukuran kualitas sinyal pada jaringan yang di uji(Cao, dkk., 2018). Metode ini merupakan bagian dari proses optimasi yang bertujuan meningkatkan kualitas dan mengembangkan daya dari suatu jaringan. Pada pola ini pengukuran kualitas sinyal untuk menghimpun data secara waktu nyata dengan cara manual yang umumnya diterapkan dalam suatu bangunan pada wilayah server dengan penambahan perangkat tambahan dalam melakukan pengujian.

\section{HASIL DAN PEMBAHASAN}

Pada bagian ini menerangkan tentang perancangan dan pengamatan dalam penelitian dengan menggunakan metode Drive Test, kemudian masuk ke tahap diskusi hasil penelitian.

\subsection{Perancangan Model yang di Pakai}

Model dalam penelitian ini dibagi menjadi beberapa langkah. Bagan alir pada gambar 1 merupakan gambran perancangan model yang di pakai mulai dari tahap awal sampai akhir. 


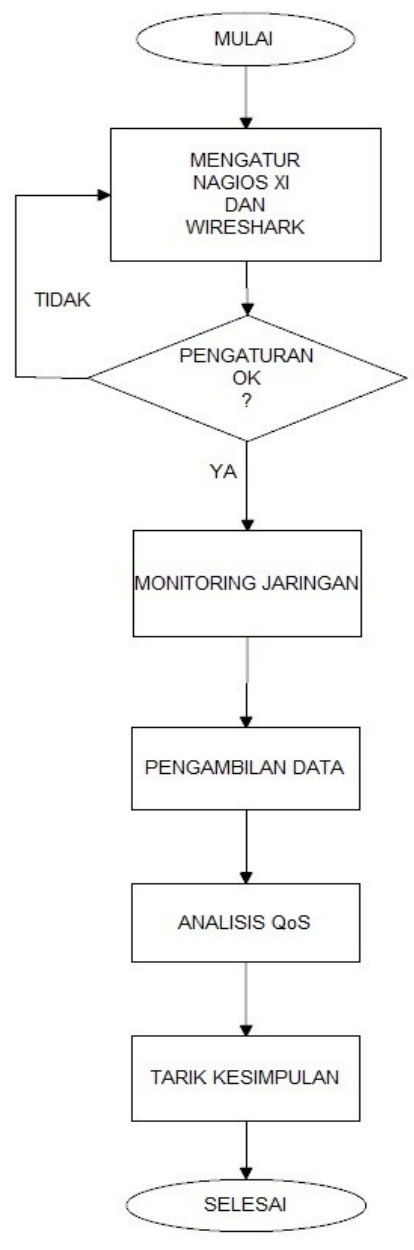

Gambar 1. Bagan alir perancangan model yang di pakai

\section{a. Mengatur Nagios XI dan Wireshark}

Dalam tahap awal ini dilakukan instalasi dan pengaturan aplikasi monitoring yang digunakan dalam penelitian ini yaitu Nagios XI dan Wireshark;

\section{b. Monitoring Jaringan}

Dalam bagian ini setelah aplikasi sudah terinstal dan diatur dengan baik tanpa ada gangguan, maka aplikasi sudah siap melakukan tahapan selanjutnya yaitu melakukan monitor jaringan pada gedung gedung di lingkungan UNIPA;

\section{c. Pengambilan Data}

Pada tahap ini aktifitas yang dilakukan adalah proses mengambil data kinerja jaringan Wi-Fi pada gedung - gedung di lingkungan UNIPA;

\section{d. Analisis QoS}

Hasil dari pemantauan dan pengambilan data kemudian di analisis menggunakan QoS, yang mana dalam penelitian ini menggunakan parameter - parameter seperti bandwidth, packet loss dan delay sebagai matrik pengujian;

\section{e. Menarik Kesimpulan}

Dari hasil analisa setiap percobaan kemudian ditarik kesimpulan, dimana dalam tahap ini dapat diketahui performa jaringan Wi-Fi dari masing - masing gedung di UNIPA.

Perangkat keras yang di gunakan dalam penelitian ini untuk mengamati performa dari Wi-Fi dapat di lihat pada Tabel 3.

\begin{tabular}{ccc}
\multicolumn{3}{c}{ Tabel 3.Perangkat Keras yang di Pakai } \\
\hline No & Jenis Perangkat & Keterangan \\
\hline \multirow{2}{*}{1} & Labtop & Asus \\
& & Vivobook \\
& & A4442U \\
& & Intel Core i5- \\
2 & CPU & $8250 \mathrm{U}$ up to \\
& & $3.4 \mathrm{GHz}$ \\
3 & Memori & $4 \mathrm{~GB}$ \\
4 & Sistem Operasi & Win 10 \\
5 & HDD & $1 \mathrm{~TB}$ \\
6 & Aplikasi Jaringan & Nagios XI dan \\
& & Wireshark \\
\hline
\end{tabular}

\subsection{Hasil Pengamatan}

Penelitian mengambil tempat di lima gedung dalam lingkungan UNIPA yakni gedung UPT. TIK UNIPA, gedung fakultas pertanian, gedung fakultas kehutanan, gedung teknik informatika dan gedung fakultas teknik.

Kemudian di lima gedung ini, jaringan di lihat performanya, percobaan di simulasikan pada masing - masing gedung dengan menggunakan tes ping, yang di ukur selama 5 hari pada jam kerja selama 5 jam. Jarak antara Access Point (AP) dengan perangkat keras yang di pakai untuk mengukur performa jaringan di setiap gedung bervariasi. Seperti pada gedung fakultas kehutanan jarak uji coba dari perangkat ke AP adalah 6 Meter, sedangkan untuk uji coba di gedung pertanian jarak antara perangkat dengan AP sejauh 8 Meter. Untuk jarak uji coba di gedung UPT. TIK UNIPA, gedung teknik informatika dan gedung fakultas teknik masing masing memiliki jarak yang sama antara perangkat uji coba dengan AP yaitu 1 Meter.

Untuk standar Wi-Fi yang di gunakan pada setiap gedung menggunakan standar IEEE 802.11n.

Kekuatan sinyal Wi-Fi yang terpantau saat melakukan percobaan pada masing - masing gedung berbeda-beda, dapat dilihat pada Tabel 4 . 


\begin{tabular}{ccc}
\multicolumn{2}{c}{ Tabel 4. Kekuatan Sinyal Wi-Fi } \\
\hline No & Gedung & $\begin{array}{c}\text { Kekuatan } \\
\text { Signal } \\
\text { (dBm) }\end{array}$ \\
\hline 1 & UPT TIK & -80 \\
2 & F.Pertanian & $-50,25$ \\
3 & F.Kehutanan & -60 \\
4 & F.Teknik & $-52,26$ \\
5 & G.T.Informatika & -73 \\
\hline
\end{tabular}

Dari hasil pengukuran sinyal Wi-FI yang di sajikan pada Tabel 4, maka dapat diketahui bahwa kekuatan sinyal pada UPT TIK UNIPA masuk dalam kategori kurang. Hal ini disebabkan karena banyak nya pengguna yang mengakses internet lewat saluran Wi-Fi ke sebuah AP yang berada pada gedung UPT TIK UNIPA di waktu yang bersamaan, maka secara otomatis ada penurunan kekuatan sinyal AP. Untuk gedung teknik informatika sinyal dikategorikan cukup untuk skala tingkat sinyal dari AP. Untuk gedung fakultas kehutanan sinyal Wi-Fi dikategorikan baik berdasarkan skala tingkat sinyal AP. Untuk gedung fakultas pertanian dan fakultas teknik masuk dalam kategori sangat baik pada kekuatan sinyal Wi-Fi, hal ini dikarenakan beban sebuah AP yang terhubung secara otomatis ke pengguna dalam waktu yang bersamaan sangat sedikit.

Dari 5 gedung yang telah di lihat kinerja jaringannya, data yang diperoleh per hari nya kemudian di kalkulasi menggunakan rumus rata-rata seperti yang terlihat pada Persamaan (3).

$\bar{x}=\frac{\sum_{i=1}^{n} x_{i}}{n}$

dimana $\bar{x}$ adalah rerata, $x_{i}$ merupakan nilai sampel data ke $-i$ dan $n$ adalah jumlah data. Setelah mendapat nilai rata-rata pada setiap percobaan maka tahap berikutnya di kalkulasi untuk memperoleh total nilai rerata.

Hasil pengukuran data yang di peroleh dengan menggunakan metode drive test di 5 gedung dalam lingkungan UNIPA, perolehan nilai rata - rata bandwidth selama 5 hari kerja, yang dapat dilihat dalam Tabel 5.

\begin{tabular}{cccc}
\multicolumn{3}{c}{ Tabel 5. Nilai rata-rata bandwidth } \\
\hline No & Gedung & $\begin{array}{c}\text { Nagios } \\
\text { XI } \\
\text { (Mbps) }\end{array}$ & $\begin{array}{c}\text { Wireshark } \\
\text { (Mbps) }\end{array}$ \\
\hline 1 & UPT TIK & 4,45 & 4,43 \\
2 & F.Pertanian & 6,39 & 6.40 \\
3 & F.Kehutanan & 4,63 & 4.64 \\
4 & F.Teknik & 5,71 & 5,71 \\
5 & G.T.Informatika & 11,86 & 11,97 \\
\hline
\end{tabular}

Dari Tabel 5 dapat di perhatikan nilai selisih bandwidth dari hasil uji coba dua aplikasi jaringan ini menunjukkan nilai selisih yang kecil, karena dipengaruhi oleh kekuatan sinyal $\mathrm{Wi}-\mathrm{Fi}$, jumlah pengguna jaringan dan jenis standar Wi-Fi pada masing-masing gedung. Seperti pada gedung fakultas pertanian walaupun jauh jarak antara AP dengan perangkat, tetapi nilai bandwidth nya lebih baik di bandingkan gedung fakultas kehutanan, fakultas teknik dan UPT TIK.

Untuk pengambilan data nilai rata - rata delay pada 5 gedung yang berada pada lingkungan UNIPA diperoleh hasil seperti Tabel 6 .

Tabel 6. Nilai rata-rata delay

\begin{tabular}{|c|c|c|c|c|}
\hline No & Gedung & $\begin{array}{c}\text { Nagios } \\
\text { XI } \\
(\mathrm{ms})\end{array}$ & $\begin{array}{c}\text { Wire } \\
\text { shark } \\
(\mathrm{ms})\end{array}$ & $\begin{array}{c}\text { Indeks } \\
\text { TIPHON }\end{array}$ \\
\hline 1 & UPT TIK & 76 & 21,8 & 4 \\
\hline 2 & F.Pertanian & 61,4 & 72,4 & 4 \\
\hline 3 & F.Kehutanan & 44,4 & 47 & 4 \\
\hline 4 & F.Teknik & 57,8 & 60,6 & 4 \\
\hline 5 & G.T.Informatika & 21,8 & 10 & 4 \\
\hline
\end{tabular}

Dari hasil pengukuran selama 5 hari pada jam kerja selama 5 jam untuk masing - masing gedung, delay paling tinggi pada gedung fakultas pertanian dan yang paling kecil tingkat delay nya adalah gedung teknik informatika. Tetapi kualitas jaringan Wi-Fi dikategorikan sangat baik karena delay pada masing - masing gedung masih $<150 \mathrm{~ms}$ dengan indeks 4 berdasarkan standar TIPHON pada Tabel 2. Hasil delay juga dipengaruhi oleh jarak, perangkat media fisik, dan waktu proses yang lama pada transfer data.

Tabel 7 adalah nilai yang diperoleh dari hasil pengamatan nilai rata - rata packet loss.

Tabel 7. Nilai rata-rata packet loss

\begin{tabular}{ccccc}
\hline No & Gedung & $\begin{array}{c}\text { Nagios } \\
\text { XI } \\
(\%)\end{array}$ & $\begin{array}{c}\text { Wire } \\
\text { shark } \\
(\mathbf{\%})\end{array}$ & $\begin{array}{c}\text { Indeks } \\
\text { TIPHON }\end{array}$ \\
\hline 1 & UPT TIK & 0 & 0 & 4 \\
2 & F.Pertanian & 0 & 0 & 4 \\
3 & F.Kehutanan & 0 & 0 & 4 \\
4 & F.Teknik & 0 & 0 & 4 \\
5 & G.T.Informatika & 0 & 0 & 4 \\
\hline
\end{tabular}

Dari tabel 7 nilai packet loss berdasarkan standar TIPHON persentase loss $0 \%$ pada setiap gedung untuk hasil pengukuran selama 5 hari pada jam kerja selama 5 jam, termasuk dalam kategori sangat bagus. Karena tidak terjadi tabrakan data dan tidak terjadi kelebihan beban dalam jaringan Wi-Fi, dalam waktu yang lama. Faktor lainnya yaitu bandwidth telah digunakakan secara maksimal.

Data tabel - tabel tersebut kemudian dianalisis optimasi kinerja QoS nya masing - masing dengan membandingkan data pada gedung - gedung yang di monitoring menggunakan aplikasi Nagios XI dan Wireshark.

\subsection{Analisa QoS}

Dalam bagian ini dijelaskan mengenai tahapan analisa QoS, hasil pengukuran dengan menggunakan metode drive test kemudian di analisa kualitas layanan jaringan Wi-Fi di gedung - gedung tersebut.

Hasil analisa yang di temukan, maka dapat diketahui bandwidth yang disediakan terpakai secara maksimal dan pemakaian tidak melebihi kapasitas 
bandwidth yang di alokasikan, sehingga tidak terjadi packet loss seperti yang tertera pada Tabel 7.

Berdasarkan standar THIPON pada tabel 1 maka dapat diperoleh perhitungan kualitas layanan jaringan WiFi dikategorikan sangat bagus dengan nilai indeks 4 untuk kategori packet loss.

Hasil analisa QoS berdasarkan rujukan standar THIPON pada tabel 2 dapat diklasifikasi kan untuk kategori delay nilai rata-rata hasil pengukuran digolongkan dalam kategori 4 yang berarti hasilnya sangat bagus, karena nilai rata-rata delay pada lima gedung rendah yaitu $<150 \mathrm{~ms}$.

\section{KESIMPULAN}

Hasil pengujian metode drive test dalam parameter QoS yang diusulkan, dimana percobaan dilakukan dengan menggunakan tes ping dapat di tarik kesimpulan sebagai berikut, kekuatan sinyal WiFi dipengaruhi oleh banyak atau sedikit pengguna yang mengakses lewat saluran Wi-Fi pada sebuah AP dalam gedung, karena mempengaruhi kekuatan sinyal AP. Jarak antara perangkat media fisik dengan AP dan juga standar teknologi Wi-Fi juga mempengaruhi kualitas layanan.

Manajemen pemakaian bandwidth dalam jaringan nirkabel sudah diatur dengan baik, sehingga tidak terjadi tabrakan atau kelebihan beban. Selain itu tidak terjadi proses transfer data yang lama, hal ini dapat dilihat dari hasil pengujian QoS untuk standar THIPON semua indeks menunjukkan nilai 4 atau sangat bagus dalam pengujian nilai delay tertinggi yang di peroleh bila di ukur dengan Nagios XI adalah $76 \mathrm{~ms}$ dan terendah adalah 21,8 ms, untuk pengukuran menggunakan Wireshark nilai tertinggi adalah 72,4 ms dan terendah adalah $10 \mathrm{~ms}$. Untuk Packet Loss hasil yang diperoleh yaitu $0 \%$ bila di ukur dengan Nagios XI dan Wireshark, sehingga masuk indeks nilai 4 atau sangat baik dalam standar THIPON.

Aplikasi Wireshark mudah di konfigurasi karena tahap instalasi nya mudah di bandingkan aplikasi Nagios XI. Untuk analisa dan kelola suatu jaringan, aplikasi Wireshark dapat melihat keadaan dari perangkat yang terkoneksi dalam jaringan Wi-Fi dengan baik. Tetapi untuk tampilan grafik hasil keluaran pemantauan packet loss Nagios XI memiliki keterangan yang lengkap untuk mengetahui paket transmisi yang mengalami kegagalan. Penerapan saat monitoring, grafik pada Nagios XI lengkap dibandingkan Wireshark yang masih memerlukan beberapa kalkulasi secara manual dari data yang tersaji pada grafik dan diagram.

Untuk hasil yang lebih akurat maka disarankan memakai beberapa parameter QoS dalam melakukan metode drive test seperti jitter dan throughput.

\section{DAFTAR PUSTAKA}

AMRON, K., PRAMUKANTORO, E.S. \& DATA, M., 2016. Pemodelan dan Analisis Wireless
Mesh Network dengan Arsitektur PublishSubscribe dan Protokol MQTT. Jurnal Teknologi Informasi dan Ilmu Komputer, 3(2), pp.88-93.

ANTODI, C.P., PRASETIJO, A.B. AND WIDIANTO, E.D., 2017. Penerapan Quality of Service Pada Jaringan Internet Menggunakan Metode Hierarchical Token Bucket. Jurnal Teknologi dan Sistem Komputer, 5(1), pp.23-28.

BANANI, S.A., ECKFORD, A.W. \& ADVE, R.S., 2015. Analyzing the Impact of Access Point Density on the Performance of Finite-Area Networks. IEEE Transactions on Communications, 63(12), pp.5143-5161.

BOBESCU, B. \& ALEXANDRU, M., 2015. Mobile indoor positioning using WI-FI localization. Review of the Air Force Academy, (1), p.119.

BOSCH, P., DE SCHEPPER, T., ZELJKOVIĆ, E., FAMAEY, J. \& LATRÉ, S., 2020. Orchestration of heterogeneous wireless networks: State of the art and remaining challenges. Computer Communications, 149, pp.62-77.

CAO, J., KONG, D., CHARITOS, M., BERKOVSKYY, D., GOULIANOS, A.A., MIZUTANI, T., TILA, F., HILTON, G., DOUFEXI, A. \& NIX, A., 2018. Design and Verification of a Virtual Drive Test Methodology for Vehicular LTE-A Applications. IEEE Transactions on Vehicular Technology, 67(5), pp.3791-3799.

GUNANTARA, N., SUDIARTA, P.K., PRASETYA, A.A.I., DHARMA, A. \& ANTARA, I.N.G., 2018. Measurements of the Received Signal Level and Service Coverage Area at the IEEE 802.11 Access Point in the Building. Journal of Physics: Conference Series, 989, p.012014.

İLÇI, V., GÜLAL, E. \& ALKAN, R.M., 2018. An investigation of different Wi-Fi signal behaviours and their effects on indoor positioning accuracy. Survey Review, 50(362), pp.404-411.

LINAWATI, L., GUNANTARA, N. \& GUNAWAN, I.K.A.R., 2015. Performansi WLAN Kantor Pusat Pemerintahan Kabupaten Badung. Majalah Ilmiah Teknologi Elektro, 14(2), pp.34-38.

MODIEGINYANE, K.M., LETSWAMOTSE, B.B., MALEKIAN, R. \& ABU-MAHFOUZ, A.M., 2018. Software defined wireless sensor networks application opportunities for efficient network management: A survey. Computers \& Electrical Engineering, 66, pp.274-287.

MODIEGINYANE, K.M., MALEKIAN, R. \& LETSWAMOTSE, B.B., 2019. Flexible network management and application service adaptability in software defined wireless 
sensor networks. Journal of Ambient Intelligence and Humanized Computing, 10(4), pp.1621-1630.

RANTELINGGI, P.H. \& DJANALI, S., 2015. Kinerja Protokol Routing Pada Lingkungan Wireless Mesh Network Dengan Combined Scalable Video Coding. JUTI: Jurnal Ilmiah Teknologi Informasi, 13(1), pp.86-94.

RANTELINGGI, P.H., PAIKI, F.F. \& RANTELOBO, K., 2017. Performance of routing protocol in MANET with combined scalable video coding. In: 2017 4th International Conference on Electrical Engineering, Computer Science and Informatics (EECSI). 2017 4th International Conference on Electrical Engineering, Computer Science and Informatics (EECSI). pp. $1-4$.

SAPUTRA, L.D.D. \& SULISTYO, W., 2017. Analisis QoS Differentiated Service pada Jaringan MPLS Menggunakan Algoritma Threshold. Jurnal Teknologi Informasi dan Ilmu Komputer, 4(4), pp.227-236.

SETIYONO, B.A.P., PRAMUKANTORO, E.S. \& AMRON, K., 2017. Pengembangan Infrastruktur Komunikasi Multigroup Pada Wi-Fi Direct. Jurnal Teknologi Informasi dan Ilmu Komputer, 4(1), pp.52-61.

SIMANJUNTAK, M.F.W., NURHAYATI, O.D. \& WIDIANTO, E.D., 2016. Analisis Quality of Service (QoS) Jaringan Telekomunikasi HighSpeed Downlink Packet Access (HSDPA) Pada Teknologi 3.5G. Jurnal Teknologi dan Sistem Komputer, 4(1), pp.67-76.

TORRES-SOSPEDRA, J., MONTOLIU, R., TRILLES, S., BELMONTE, Ó. \& HUERTA, J., 2015. Comprehensive analysis of distance and similarity measures for Wi-Fi fingerprinting indoor positioning systems. Expert Systems with Applications, 42(23), pp.9263-9278.

WULANDARI, R., 2016. Analisis Qos (Quality Of Service) Pada Jaringan Internet (Studi Kasus : Upt Loka Uji Teknik Penambangan Jampang Kulon - Lipi). Jurnal Teknik Informatika dan Sistem Informasi, 2(2), pp.162-172.

WULANDARI, T., PERDANA, D. \& NEGARA, R.M., 2017. Analisis Unjuk Kerja Perubahan Jumlah Node dan RAW Station pada IEEE 802.11ah. Jurnal Nasional Teknik Elektro dan Teknologi Informasi (JNTETI), 6(3), pp.326332.

XIE, Y., WANG, Y., NALLANATHAN, A. \& WANG, L., 2016. An Improved K-NearestNeighbor Indoor Localization Method Based on Spearman Distance. IEEE Signal Processing Letters, 23(3), pp.351-355.

YU, F., JIANG, M., LIANG, J., QIN, X., HU, M., PENG, T. \& HU, X., 2014. 5 G WiFi SignalBased Indoor Localization System Using
Cluster k-Nearest Neighbor Algorithm. International Journal of Distributed Sensor Networks, 10(12), p.247525. 
Halaman ini sengaja dikosongkan 